OPEN ACCESS

Edited by:

Luca Antonioli,

University of Pisa, Italy

Reviewed by:

Matteo Fornai,

University of Pisa, Italy

Ricard Farre,

KU Leuven, Belgium

${ }^{*}$ Correspondence:

Giuseppe Esposito

giuseppe.esposito@uniroma1.it

Giovanni Sarnelli

sarnelli@unina.it

${ }^{+}$These authors have contributed equally to this work

Specialty section: This article was submitted to Gastrointestinal and Hepatic Pharmacology,

a section of the journal

Frontiers in Pharmacology

Received: 09 December 2020

Accepted: 01 March 2021

Published: 27 April 2021

Citation:

Esposito G, Corpetti C, Pesce M, Seguella L, Annunziata G, Del Re A,

Vincenzi M, Lattanzi R, Lu J, Sanseverino W and Sarnelli G (2021) A

Palmitoylethanolamide Producing

Lactobacillus paracasei Improves

Clostridium difficile Toxin A-

Induced Colitis.

Front. Pharmacol. 12:639728.

doi: 10.3389/fphar.2021.639728

\section{A Palmitoylethanolamide Producing Lactobacillus paracasei Improves Clostridium difficile Toxin A-Induced Colitis}

\author{
Giuseppe Esposito ${ }^{1,2 * t}$, Chiara Corpetti ${ }^{1 \dagger}$, Marcella Pesce ${ }^{3 t}$, Luisa Seguella ${ }^{1}$, \\ Giuseppe Annunziata ${ }^{4}$, Alessandro Del Re ${ }^{1}$, Martina Vincenzi ${ }^{1}$, Roberta Lattanzi ${ }^{1}$, Jie $L^{5}{ }^{5}$, \\ Walter Sanseverino ${ }^{2}$ and Giovanni Sarnelli ${ }^{3,2,6 *}$ \\ ${ }^{1}$ Department of Physiology and Pharmacology, "V. Erspamer", Sapienza University of Rome, Rome, Italy, ${ }^{2}$ Nextbiomics S.r.l., \\ Naples, Italy, ${ }^{3}$ Department of Clinical Medicine and Surgery, Section of Gastroenterology, University Federico II, Naples, Italy, \\ ${ }^{4}$ Department of Pharmacy, Faculty of Pharmacy, University Federico II, Naples, Italy, ${ }^{5}$ Department of Human Anatomy, College of \\ Basic Medical Sciences, China Medical University, Shenyang, China, ${ }^{6}$ UNESCO Chair Staff Member, University of Naples \\ "Federico II", Naples, Italy
}

Genetically engineered probiotics, able to in situ deliver therapeutically active compounds while restoring gut eubiosis, could represent an attractive therapeutic alternative in Clostridium difficile infection (CDI). Palmitoylethanolamide is an endogenous lipid able to exert immunomodulatory activities and restore epithelial barrier integrity in human models of colitis, by binding the peroxisome proliferator-activated receptor- $\alpha$ (PPAR $\alpha$ ). The aim of this study was to explore the efficacy of a newly designed PEA-producing probiotic (pNAPE-LP) in a mice model of $C$. difficile toxin A (TcdA)-induced colitis. The human N-acyl-phosphatidylethanolamine-specific phospholipase D (NAPE-PLD), a key enzyme involved in the synthesis of PEA, was cloned and expressed in a Lactobacillus paracasei that was intragastrically administered to mice 7 days prior the induction of the colitis. Bacteria carrying the empty vector served as negative controls (pLP).In the presence of palmitate, PNAPE-LP was able to significantly increase PEA production by 27,900\%, in a time- and concentration-dependent fashion. Mice treated with pNAPE-LP showed a significant improvement of colitis in terms of histological damage score, macrophage count, and myeloperoxidase levels $(-53,-82$, and $-70.4 \%$, respectively). This was paralleled by a significant decrease both in the expression of toll-like receptor-4 (-71\%), phospho-p38 mitogen-activated protein kinase (-72\%), hypoxia-inducible factor1-alpha (-53\%), p50 (-74\%), and p65 (-60\%) and in the plasmatic levels of interleukin-6 $(-86 \%)$, nitric oxide $(-59 \%)$, and vascular endothelial growth factor $(-71 \%)$. Finally, tight junction protein expression was significantly improved by pNAPE-LP treatment as witnessed by the rescue of zonula occludens-1 (+304\%), Ras homolog family member A-GTP (+649\%), and occludin expression (+160\%). These protective effects were mediated by the specific release of PEA by the engineered probiotic as they were abolished in PPARa knockout mice and in wild-type mice treated with pLP. Herein, we demonstrated that pNAPE-LP has therapeutic potential in CDI by inhibiting colonic 


\section{inflammation and restoring tight junction protein expression in mice, paving the way to next} generation probiotics as a promising strategy in CDI prevention.

Keywords: palmitoylethanolamide, Clostridium difficile toxin A, colitis, Lactobacillus paracasei, next generation probiotics

\section{INTRODUCTION}

Clostridium (Clostridioides) difficile infection (CDI) represents the leading cause of nosocomial diarrhea in North America and Europe and has been labeled as an urgent public health threat by the US Center for Disease Control and Prevention (CDC) (Lessa et al., 2015). The disease almost invariably follows a disruption of gut resident flora, allowing $C$. difficile colonization and germination of the colon, commonly caused by broadspectrum antibiotic use. Recent estimates indicate that $C$. difficile strains can be found in up to $50 \%$ of asymptomatic hospitalized patients; while in symptomatic individuals, the clinical spectrum may vary from uncomplicated diarrhea to even lethal pseudomembranous colitis, depending on strain virulence, on one hand and intestinal microecological conditions (competitive colonization resistance from host microflora), on the other (Napolitano and Edmiston, 2017).

C. difficile virulence depends on two bacterial exotoxins, $C$. difficile toxin $\mathrm{A}$ and $\mathrm{B}$ (TcdA and $\mathrm{B}$, respectively) (Schäffler and Breitrück, 2018), that are internalized into the host cells via receptor-mediated endocytosis and inhibited by glycosylation Ras homolog family member A-GTPase (RhoA-GTPase) (Chen et al., 2015). RhoA-GTPase proteins are physiologically involved in actin cytoskeleton and tight junctions' assembly (Terry et al., 2010), resulting in the disruption of the epithelial barrier, and consequently, a profound inflammatory response with release of pro-inflammatory cytokines and extensive neutrophil infiltration, through activation of the nuclear factor-kappa B (NF- $\mathrm{B}$ ) signaling pathway (Kim et al., 2006).

Palmitoylethanolamide (PEA) is an endogenous, on demandreleased $\mathrm{N}$-acylethanolamine belonging to the family of bioactive autacoid local injury antagonist amides (ALIAmides), a group of lipid molecules involved in the regulation of several physiological processes, ranging from analgesia, neuroprotection, and inflammation (Petrosino and Di Marzo, 2017). By selectively binding the peroxisome proliferator-activated receptor- $\alpha$ (PPARa) (Sarnelli et al., 2016b), PEA exerts a wide range of anti-inflammatory effects, downregulating inducible nitric oxide synthase (iNOS), cycloxigenase-2 (COX-2), tumor necrosis factor- $\alpha$ (TNF- $\alpha$ ) expression, and the NF- $\kappa B$ signaling pathway, with downstream regulation of pro-inflammatory cytokines and immune cell infiltration in inflamed tissues. PEA anti-inflammatory effects have been tested in other animal models of colitis and in human-derived biopsies culture from ulcerative colitis patients. However, to date its potential in models of Clostridium difficile-induced colitis remains to be established (Esposito et al., 2014; Pesce et al., 2018).

PEA is produced by conjugation from palmitate and ethanolamine, through the $\mathrm{N}$-acyl-phosphatidylethanolaminespecific phospholipase D (NAPE-PLD) (Pesce et al., 2018), a key enzyme in both ALIAmides and endocannabinoid synthesis and is rapidly degraded after binding its receptor targets. Owing to its on-demand activity, PEA is safe and virtually free from side effects but requires high doses to achieve significant pharmacological effects. From a translational standpoint, this unfavorable pharmacokinetic profile is a major setback in PEA translatability to clinical contexts. It is therefore pivotal to develop new formulations and/or delivery systems able to increase PEA tissue exposure, enhancing its contact surface in the attempt of achieving an efficient therapeutic response.

To overcome this limitation, we developed a probiotic-based delivery system, by genetically engineering Lactobacillus paracasei subsp. paracasei F19 with the human NAPE-PLD gene (p-NAPE-LP), in order to achieve an in situ delivery and release of PEA in the gastrointestinal tract, under the boost of ultralow doses of exogenous palmitate. Lactobacilli are able to survive the gastrointestinal tract and colonize the large intestine, where they constitute part of the endogenous microflora. They are recognized as safe (GRAS) for human consumption, making them suitable vehicles to deliver therapeutic molecules in the large intestine. Based on this background, we tested the efficacy of daily intragastric administration of p-NAPE-LP in preventing the severity of colitis induced by intrarectal instillation of TcdA, a well-validated murine model that resembles the most important features observed in CDI in humans (Markham et al., 2020).

\section{MATERIALS AND METHODS}

\section{Generation of Genetically Modified Strains of Lactobacillus paracasei Subsp. Paracasei F19 (pNAPE-LP)}

The pTRKH3-slpGFP vector (Addgene, Watertown, Massachusetts, United States) was first modified to remove the GFP sequence at SalI/PstI restriction sites, insert the T7 transcriptional terminator at BamHI/EcoRV sites, and insert the linker sequence containing BsaI-BsaI at PstI/XmaI restriction sites. The cDNA of human NAPE-PLD was then inserted into the BsaI sites using In-Fusion method (Clontech, Mountain View, CA, United States). The resulting pTRKH3-slpNAPE-PLD and parental plasmid (not expressing NAPE-PLD gene, used as negative control) constructs were transfected into the L. paracasei subsp. paracasei F19 strain (Arla Foods, Hoersholm, Denmark) by electroporation, and positive clones were obtained by erythromycin $(5 \mu \mathrm{g} / \mathrm{ml})$ selection. Both parental plasmid (pLP) and NAPE-PLD expressing bacteria (pNAPE-LP) were amplified anaerobically in Man, Rogosa, and Sharpe (MRS) broth (Conda, Torrejón de Ardoz Madrid, Spain) and isolated in MRS agar (Conda, Torrejón de Ardoz Madrid, Spain) both 


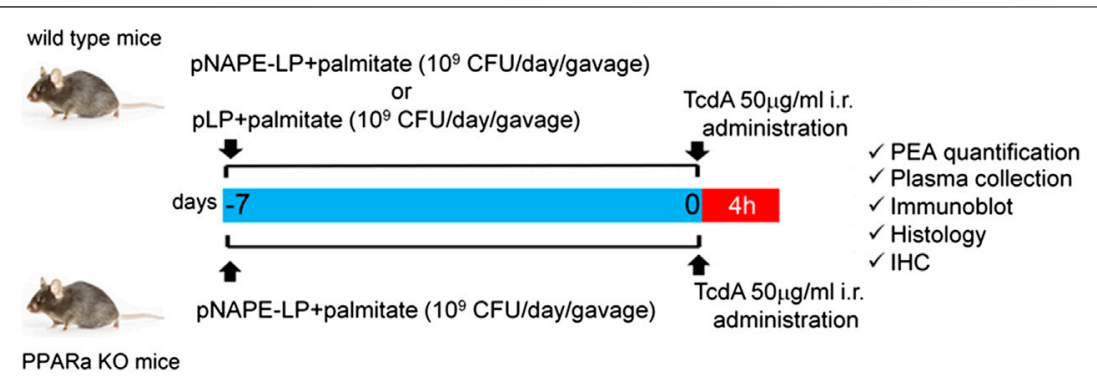

SCHEME 1 | Experimental plan description: both wild type and PPAR $\alpha \mathrm{KO}$ mice received a daily prophylactic gavage administration of either pNAPE-LP (10 ${ }^{9} \mathrm{CFU}$ ) or pLP $\left(10^{9} \mathrm{CFU}\right) 200 \mu \mathrm{l}$ suspensions with sodium palmitate $(0.0003 \mu \mathrm{g} / \mathrm{ml})$. At day 7 , animals received a single intrarectal instillation of TcdA (50 $\left.\mu \mathrm{g} / \mathrm{ml}\right)$. Animals were euthanized $4 \mathrm{~h}$ later and PEA quantification and other molecular/histological analyses were thus carried on postmortem isolated colonic tissue or related samples.

supplemented with erythromycin $5 \mu \mathrm{g} / \mathrm{ml}$ (Sigma-Aldrich, Milan, Italy) under anaerobic conditions for $72 \mathrm{~h}$ at $37^{\circ} \mathrm{C}$. Bacteria viability was determined by manually counting colonies, and the colony forming units $(\mathrm{CFU}) / \mathrm{ml}$ was obtained through a colony number correction for the dilution factor.

\section{Animals and Experimental Design}

Six-week-old wild-type (WT) male C57BL/6J (Charles River, Laboratories, Italy) and PPARa knockout (KO) (Taconic, Germantown, New York, United States) mice were used for the experiments. All the procedures were approved by $\mathrm{La}$ Sapienza University's Ethics Committee in compliance with the IASP and European Community (EC L358/1 18/12/86) guidelines on the use and protection of animals in experimental research. As depicted in Scheme 1, C57BL/6J mice were randomly divided into four experimental groups ( $n=10$ per group): 1 ) vehicle (control group); 2) TcdA group; 3) $\mathrm{TcdA}+\mathrm{pLP}$ group; and 4) TcdA + pNAPE-LP group, respectively. Both vehicle and TcdA groups received $200 \mu \mathrm{l}$ MRS broth by intragastric gavage for one week, while the TcdA + pLP group was administered a daily volume of $200 \mu \mathrm{l}$ of MRS broth suspension containing $10^{9} \mathrm{CFU}$ of pLP strain with $0.0003 \mu \mathrm{g} / \mathrm{ml}$ of sodium palmitate (Sigma-Aldrich, Milan, Italy). In the same conditions, the TcdA + pNAPE-LP group was administered by intragastric gavage with a daily volume of $200 \mu \mathrm{l}$ of MRS broth suspension containing $10^{9} \mathrm{CFU}$ of pNAPE-LP and $0.0003 \mu \mathrm{g} / \mathrm{ml}$ of sodium palmitate. PPARa KO mice were randomly divided into three experimental groups $(n=$ 6 per group): 1) vehicle (control group); 2) TcdA group; and 3) TcdA + pNAPE-LP group, respectively, and treated as above. One week following probiotic administration, mice received by intrarectal route, a single administration of phosphate buffered saline $1 \times($ PBS $1 \times)$ or TcdA $(50 \mu \mathrm{g} / \mathrm{ml}$ dissolved in PBS $1 \times)$, according to the method described by Hirota et al. (2012) to induce acute pseudomembranous colitis. Since animals' death was not an acceptable experimental end point, based on the Institutional Animal Care and Use Committee (which ethically prevents the death of the animal as a terminal event of the procedure), we used a nonlethal dose of TcdA, and after $4 \mathrm{~h}$ from the intrarectal administration, all mice used for the experimental plan were deeply anesthetized before being euthanatized, as described by Hirota et al. (2012). Blood samples were collected by intracardiac puncture, and tissues were isolated and processed to further analyses (see below).

\section{Extraction and Quantification of In Vitro and In Vivo Produced PEA by HPLC-MS Method}

Extraction and analysis of PEA released in vitro and in vivo were performed according to Gachet et al. (Gachet et al., 2015), with slight modifications. Bacterial cultures were ultracentrifuged at $14,000 \mathrm{rpm}$ for $10 \mathrm{~min}$ to separate the culture medium and bacterial pellet. Culture media were freeze-dried and then resuspended in a solution containing acetonitrile with $0.1 \%$ formic acid (extraction solution). Then, the samples were ultracentrifuged $\left(14,000 \mathrm{rpm}, 4^{\circ} \mathrm{C}, 5 \mathrm{~min}\right)$ and the supernatant injected for the mass spectrometry analysis. Both bacterial pellet and mice colonic tissues were firstly lysed using a lysis buffer and then evaporated under a nitrogen stream. Residues were suspended in extraction solution, ultra-centrifuged $\left(14,000 \mathrm{rpm}, 4^{\circ} \mathrm{C}, 5 \mathrm{~min}\right)$, and the supernatant injected for the mass spectrometry analysis. Analyses were run on a Jasco Extrema LC-4000 system (Jasco Inc., Easton, MD) coupled to an Advion Expression mass spectrometer (Advion Inc., Ithaca, NY) equipped with an electrospray (ESI) source. Mass spectra were recorded in the positive SIM mode. The capillary voltage was set at $+180 \mathrm{~V}$, the spray voltage was at $3 \mathrm{kV}$, the source voltage offset was at $+20 \mathrm{~V}$, and the capillary temperature was set at $250^{\circ} \mathrm{C}$. The chromatographic separation was performed on analytical column Kinetex C18 $(150 \times 4.6 \mathrm{~mm}$, id. $3 \mu \mathrm{m}, 100 \AA ̊)$ and security guard column both supplied by Phenomenex (Torrance, CA, United States). The analyses were performed at a flow rate of $0.3 \mathrm{ml} / \mathrm{min}$, with solvent A (water containing $2 \mathrm{mM}$ ammonium acetate) and solvent $\mathrm{B}$ (methanol containing $2 \mathrm{mM}$ ammonium acetate and $0.1 \%$ formic acid). Elution was performed according to the following linear gradient: $15 \% \mathrm{~B}$ for $0.5 \mathrm{~min}, 15-70 \% \mathrm{~B}$ from 0.5 to $2.5 \mathrm{~min}, 7-99 \% \mathrm{~B}$ from 2.5 to $4.0 \mathrm{~min}$, and held at $99 \% \mathrm{~B}$ from 4.0 to $8.0 \mathrm{~min}$. From 8 to $11.50 \mathrm{~min}$, the column was equilibrated to $15 \% \mathrm{~B}$ and conditioned from 11.5 to 15.0 at $15 \%$ B. The injection volume was $10 \mu \mathrm{l}$, and the column temperature was fixed at $40^{\circ} \mathrm{C}$. For quantitative analysis, standard curves of PEA (Sigma-Aldrich, Milan, Italy) were prepared over a concentration range of $0.0001-10 \mathrm{ppm}$ with six different concentration levels and 
duplicate injections at each level. All data were collected and processed using JASCO ChromNAV (version 2.02.04) and Advion Data Express (4.0.13.8).

\section{Histopathological Analysis}

After sacrifice, mice distal colon specimens were fixed in $4 \%$ paraformaldehyde (PFA), sectioned into $15 \mu \mathrm{m}$ slices, and stained with hematoxylin and eosin ( $\mathrm{H}$ and $\mathrm{E})$ (Sigma-Aldrich, Milan, Italy) for macroscopic and histopathological assessment. Colonic histological damage was evaluated through a complex score, according to the criteria proposed (Li et al., 2017), considering the following parameters: 1) distortion and loss of crypt architecture $(0=$ none; $1=$ mild; $2=$ moderate; $3=$ severe $)$; 2) infiltration of inflammatory cells $(0=$ normal; $1=$ mild infiltration; 2 = moderate infiltration; 3 = dense infiltration); 3) muscle thickening $(0=$ normal; $1=$ mild muscle thickening; $2=$ moderate muscle thickening; 3 = marked muscle thickening); 4) goblet cells depletion ( $0=$ absence; $1=$ presence $)$; and 5$)$ crypt absence $(0=$ absence; $1=$ presence $)$. Slices were analyzed with a microscope Optika XDS-3L4 Ponteranica, BG, Italy), and images were captured at $4 \times$ magnification by a high-resolution digital camera (Nikon Digital Sight DS-U1). The cumulative histological damage score was expressed as average scores in each experimental group derived by the observations of two independent qualified observers (CC and GE).

\section{Determination of Macrophages Mucosal Infiltration}

Samples for immunohistochemical assessment of macrophages were isolated from both WT and PPAR $\alpha$ KO mouse distal colon. Tissues were fixed in 4\% PFA, embedded in paraffin, sectioned in $15 \mu \mathrm{m}$ slices, and processed for immunohistochemistry. Slices were pretreated using heat-mediated antigen retrieval with a sodium citrate buffer, incubated with MAC387 (Abcam, Cambridge, United Kingdom) at room temperature (RT) (Thoree et al., 2008), and detected using the horseradish peroxidase (HRP)-conjugated compact polymer system. 3,30diaminobenzidine (DAB) was used as the chromogen. Slices were then counterstained with hematoxylin, mounted with Eukitt (Sigma-Aldrich, Milan, Italy), and analyzed with a microscope (Optika XDS-3L4 Ponteranica, BG, Italy). Images were captured at $10 \times$ with a high-resolution digital camera and the data represent the median results of the two blinded assessors (CC and GE); in all cases, results of the assessments differed by no more than $5 \%$. Results were quantified by ImageJ software (National Institutes of Health) and expressed as the number of macrophage marker antibody (MAC387) positive cells per area.

\section{Myeloperoxidase Assay}

Myeloperoxidase (MPO), a marker of polymorphonuclear leukocyte accumulation, was determined as previously described (Mullane et al., 1985). After removal, colonic tissues from both WT and PPARa KO mice were rinsed with a cold saline solution, opened, and deprived of the mucosa using a glass slide. The resulting layer was then homogenized in a solution containing $0.5 \%$ hexadecyltrimethylammonium bromide
(Sigma-Aldrich, Milan, Italy), dissolved in $10 \mathrm{mM}$ potassium phosphate buffer, and centrifuged for $30 \mathrm{~min}$ at $20,000 \times \mathrm{g}$ at $37^{\circ} \mathrm{C}$. An aliquot of the supernatant was mixed with a solution of tetramethylbenzidine (1.6 mM; Sigma-Aldrich, Milan, Italy) and $0.1 \mathrm{mM}$ hydrogen peroxide (Sigma-Aldrich, Milan, Italy). The solution was then spectrophotometrically measured at $650 \mathrm{~nm}$. MPO activity was determined as the amount of enzyme degrading $1 \mathrm{mmol} / \mathrm{min}$ of peroxide at $37^{\circ} \mathrm{C}$ and was expressed in milliunits $(\mathrm{mu})$ per $100 \mathrm{mg}$ of wet tissue weight.

\section{Protein Extraction and Western Blot Analysis}

Proteins were extracted from colonic tissue or bacteria pellets and processed by Western blot analysis. For protein extraction by the bacterial pellet, a specific CelLytic ${ }^{\mathrm{TM}}$ lysis buffer (Sigma-Aldrich, Milan, Italy) was used according to manufacturer's instructions. Tissue samples were homogenized in ice-cold hypotonic lysis buffer [10 mM 4-(2-hydroxyethyl)-1-piperazineethanesulfonic acid (HEPES), $1.5 \mathrm{mM} \mathrm{MgCl}_{2}, \quad 10 \mathrm{mM} \mathrm{KCl}, \quad 0.5 \mathrm{mM}$ phenylmethylsulphonylfluoride, $1.5 \mu \mathrm{g} / \mathrm{ml}$ soybean trypsin inhibitor, $7 \mathrm{mg} / \mathrm{ml}$ pepstatin $\mathrm{A}, 5 \mathrm{mg} / \mathrm{ml}$ leupeptin, $0.1 \mathrm{mM}$ benzamidine, and $0.5 \mathrm{mM}$ dithiothreitol (DTT)]. Both bacterial- and tissue-deriving protein extracts were mixed with a nonreducing gel loading buffer [50 mM Tris (hydroxymethyl) aminomethane (Tris), $10 \%$ sodium dodecyl sulfate (SDS), $10 \%$ glycerol, $2 \mathrm{mg} / \mathrm{ml}$ bromophenol] at a 1:1 ratio, and then boiled for $3 \mathrm{~min}$ followed by centrifugation at $10,000 \times \mathrm{g}$ for $10 \mathrm{~min}$. The protein concentration was determined using Bradford assay and equivalent amounts $(50 \mu \mathrm{g})$ of each homogenate underwent electrophoresis through a polyacrilamide minigel. After the transfer the membranes were incubated with $10 \%$ nonfat dry milk in PBS overnight at $4^{\circ} \mathrm{C}$ and then exposed, depending on the experiments, with rabbit polyclonal anti-NAPE-PLD (Abcam, Cambridge, United Kingdom) (1:200 v/v), rabbit polyclonal anti-toll-like receptor-4 (TLR4) (Bioss Antibodies, Boston, United States) (1:1,000 v/v), mouse monoclonal anti-RhoAGTPase (Santa Cruz Biotechnology, Santa Cruz, CA, United States) (1:100 v/v), rabbit polyclonal anti-p38 mitogen-activated protein kinase (p38 MAPK) (Bioss Antibodies, Boston, United States $(1: 1,000 \mathrm{v} / \mathrm{v})$, rabbit monoclonal anti-phospho-p-38 (p-p38) MAPK (Santa Cruz Biotechnology, Santa Cruz, CA, United States) (1:1,000 v/v), rabbit polyclonal anti-NF- $\mathrm{kB}$ p65 (Sigma-Aldrich, Milan, Italy) $(1: 1,000 \mathrm{v} / \mathrm{v})$, mouse monoclonal anti-NF- $\mathrm{B}$ p50 (Santa Cruz Biotechnology, Santa Cruz, CA, United States) (1:1,000 v/v), mouse monoclonal anti-hypoxia-inducible factor-1-alpha (HIF-1a) (Novus biological, Abingdon, United Kingdom) (1: $500 \mathrm{v} / \mathrm{v})$, and rabbit polyclonal anti-glyceraldehyde 3-phosphate dehydrogenase (GAPDH) (Cell Signaling Technology, Danvers, MA, United States $)(1: 1,000 \mathrm{v} / \mathrm{v})$ according to standard experimental protocols. Membranes were then incubated with the specific secondary antibodies conjugated to HRP (Dako, Milan, Italy). Immune complexes were exposed to enhanced chemiluminescence detection reagents, and the blots were analyzed by scanning densitometry (Versadoc MP4000; Bio-Rad, Segrate, Italy). Results were expressed as 

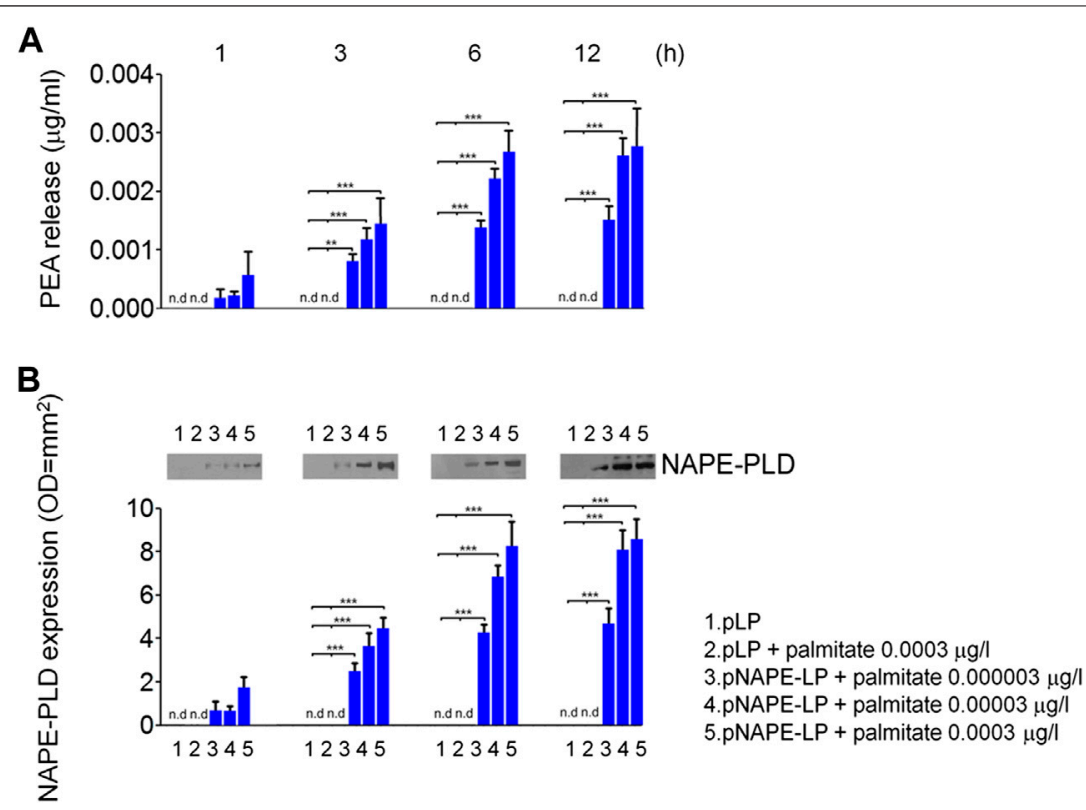

FIGURE 1 | PEA is released in vitro by engineered NAPE-PLD Lactobacillus paracasei under palmitate dose and time dependent boost. (A) PEA release was evaluated in bacterial supernatants at $1,3,6$, and $12 \mathrm{~h}$, respectively, by HPLC-MS, and the results are expressed as mean \pm SEM of $n=4$ experiments performed in triplicate. Compared with pLP in absence of palmitate supply, exogenous palmitate $(0.000003-0.0003 \mu \mathrm{g} / \mathrm{l})$ dose- and time-dependently increased PEA release from pNAPE-LP probiotics, ${ }^{* \star *} p<0.001,{ }^{* *} p<0.01 \mathrm{vs}$. both $\mathrm{pLP}$ and $\mathrm{pLP}$ in presence of palmitate $0.0003 \mu \mathrm{g} / \mathrm{l}$. PEA levels were undetectable in pLP supernatants, even in the presence of the highest tested doses of exogenous palmitate $(0.0003 \mu \mathrm{g} /)$. In the same conditions, (B) Western blot analysis of NAPE-PLD expression and relative densitometric analysis of immunoreactive bands show that NAPE-PLD protein expression is time (1, 3, 6, and $12 \mathrm{~h}$ ) and palmitate concentration (0.000003-0.0003 $\mu \mathrm{g} / \mathrm{l})$ dependent in pNAPE-LP engineered bacteria, whereas no expression was noticeable in pLP alone at the different time points, even in the presence of the highest palmitate doses $(0.0003 \mu \mathrm{g} / \mathrm{l}) .{ }^{* \star \star} \mathrm{p}<0.001 \mathrm{vs}$. both $\mathrm{pLP}$ and $\mathrm{pLP}+$ palmitate $0.0003 \mu \mathrm{g} / \mathrm{l}$. d., non-detectable.

optical density $\left(\mathrm{OD}\right.$; arbitrary units $=\mathrm{mm}^{2}$ ) and normalized against the expression of the housekeeping protein GAPDH. Immune complexes were revealed by enhanced chemiluminescence detection reagents (Amersham Biosciences, Milan, Italy) and exposed to the Kodak X-Omat film (Eastman Kodak Co., Rochester, NY, United States OK). Protein bands were then scanned and densitometrically analyzed with a GS-700 imaging densitometer. Results were expressed as OD (arbitrary units; $\mathrm{mm}^{2}$ ) and normalized on the expression of the housekeeping protein GAPDH for mice and proteins.

\section{Blood Samples Preparation}

Before being sacrificed, mice were deeply anesthetized. Blood samples were taken by cardiac puncture and collected in 5\% ethylenediaminetetraacetic acid (EDTA) vials, immediately prior to sacrifice. To determine nitric oxide (NO), interleukin-6 (IL-6), and vascular endothelial growth factor (VEGF) levels, plasma was then isolated from the blood, immediately frozen, and stored at $-80^{\circ} \mathrm{C}$ until the assays.

\section{Enzyme-Linked Immunosorbent Assay for IL-6 and VEGF}

Enzyme-linked immunosorbent assay (ELISA) for IL-6 and VEGF (all from Thermo Fisher Scientific Inc., Monza, Italy) was carried out on mice plasma according to the manufacturer's protocol. Absorbance was measured on a microtiter plate reader. IL-6 and VEGF levels were determined using the standard curves method.

\section{NO Quantification}

NO production was measured as nitrite $\left(\mathrm{NO}_{2}{ }^{-}\right)$ accumulation in murine plasma by a spectrophotometer assay based on the Griess reaction (Di Rosa et al., 1990). Briefly, Griess reagent $(1 \%$ sulfanilamide and $0.1 \%$ naphthylethylenediamine in $\mathrm{H}_{3} \mathrm{PO}_{4}$ ) was added to an equal volume of plasma, and the absorbance was measured at $550 \mathrm{~nm} . \mathrm{NO}_{2}{ }^{-}$concentration $(\mathrm{nm})$ was thus determined using a standard curve of $\mathrm{NaNO}_{2}$.

\section{Immunofluorescence Analysis for Mucosal ZO-1 and Occludin}

Segments of distal mouse colon were isolated and fixed in ice-cold $4 \%$ PFA and sectioned into $20 \mu \mathrm{m}$ slices. Sections were thus blocked with bovine serum albumin and subsequently stained with mouse anti-zonula occludens-1 (ZO-1) antibody (Bioss Antibodies, Boston, United States) $(1: 100 \mathrm{v} / \mathrm{v})$ or rabbit anti-occludin antibody (Novus biological, Abingdon, United Kingdom) (1:100 $\mathrm{v} / \mathrm{v})$. Slices were then washed with PBS $1 \times$ and incubated in the dark with fluorescein isothiocyanate-conjugated anti-rabbit (Abcam, Cambridge, United Kingdom). Nuclei were stained 


\section{A}

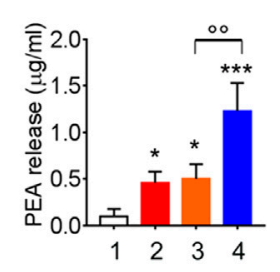

C

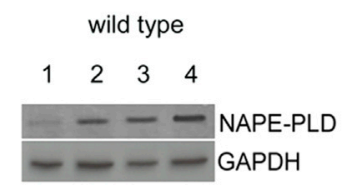

E

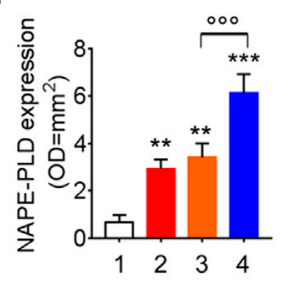

$1 \square$ Vehicle

2 TcdA $50 \mathrm{ng} / \mathrm{ml}$

3 TcdA $50 \mathrm{ng} / \mathrm{ml}+$ pLP+palmitate $0.0003 \mu \mathrm{g} / \mathrm{ml}$

4 TCdA $50 \mathrm{ng} / \mathrm{ml}+$ pNAPE-LP + palmitate $0.0003 \mu \mathrm{g} / \mathrm{m}$
B

PPAR $\alpha \mathrm{KO}$

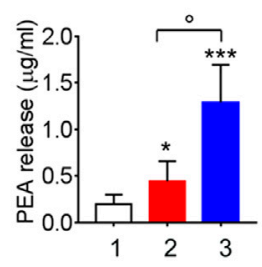

D

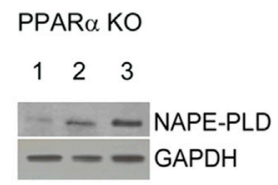

$\mathbf{F}$

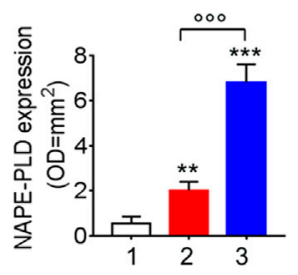

10 Vehicle

2 TcdA $50 \mathrm{ng} / \mathrm{ml}$
3 TcdA $50 \mathrm{ng} / \mathrm{ml}$ + pNAPE-LP +palmitate $0.0003 \mu \mathrm{gg} / \mathrm{ml}$

FIGURE 2 | PEA is released in vivo by engineered NAPE-PLD probiotic under palmitate dose- and time-dependent boost. PEA levels were measured in both wild type (A) and PPAR $\alpha$ KO mice (B) colon by HPLC-MS, and results are expressed as mean \pm SEM of $n=6$ experiments performed in triplicate. TcdA challenge caused PEA increase in both mice types $\left({ }^{*} p<0.05\right.$ vs. respective controls). Figures (A) and (B) show that pNAPE-LP + palmitate $(0.0003 \mu \mathrm{g} / \mathrm{kg})$, resulted in a significantly increased PEA release as compared to vehicle (both ${ }^{* \star *} p<0.001$ vs. vehicle) and TcdA-treated groups in both wild type and PPARa KO mice $\left({ }^{000} p<0.001\right.$ and ${ }^{\circ} p<0.01$ and ${ }^{\circ} p<0.05$ vs. respective TcdA groups). Figure also shows Western blot analysis of NAPE-PLD expression and relative densitometric analysis of immunoreactive bands in both wild type (C) and PPAR $\mathrm{KO}$ mice (D) colon and their relative densitometric quantification (E, F). Results are expressed as mean \pm SEM of $n=6$ experiments performed in triplicate. The TcdA challenge caused an increased expression of NAPE-PLD in both mice types $\left({ }^{* *} p<0.01\right.$ vs. respective controls). pNAPE-LP and palmitate $(0.0003 \mu \mathrm{g} / \mathrm{kg}$ ) supply resulted in a significantly higher NAPE-PLD protein expression in the colon of both untreated mice types (both ${ }^{\star \star *} p<0.001$ vs. vehicle) (C-F), and in both wild type and PPARa KO mice treated with TcdA (both ${ }^{000} p<0.001$ vs. respective TcdA groups).

with 2-(4-amidinophenyl)-1H -indole-6-carboxamidine (DAPI) (Thermo Fisher Scientific, Massachusetts, United States). Sections were analyzed with a microscope (Optika XDS-3FL4 Ponteranica, BG, Italy), and images were captured by a highresolution digital camera (Nikon Digital Sight DS-U1). The expression of zonula occludens (ZO-1) and occludin was measured as relative fluorescence units (RFU) fold change vs. vehicle groups.

\section{Statistical Analysis}

Results are expressed as the mean \pm standard error (SEM) of $n$ sets of experiments in triplicate (see figure legends). Statistical analyses were performed using one-way analysis of variance, and multiple comparisons were performed using a Bonferroni post hoc test. ${ }^{*} p<0.05,{ }^{* *} p<0.01$, and ${ }^{* * *} p<0.001$ were considered to indicate a statistically significant difference vs. control group, and ${ }^{\circ} p<0.05,{ }^{\circ o} p<0.01$, and ${ }^{\circ o o} p<0.001$ were considered to indicate a statistically significant difference vs. TcdA group.

\section{RESULTS}

\section{Time- and palmitate concentration-dependent NAPE-PLD expression and PEA release by pNAPE-LP engineered bacteria in vitro}

We first evaluated in vitro the ability of pNAPE-LP engineered strains to release PEA in the bacterial supernatant under the boost of the ultralow dose of exogenous palmitate and tested the optimal palmitate concentrations to use in our in vivo experiments. Our results demonstrated that NAPE-PLD protein expression increased in a time-dependent manner in pNAPE-LP bacteria, following culture medium supplementation with $0.000003-0.0003 \mu \mathrm{g} / \mathrm{ml}$ of palmitate, reaching an expression peak between 6 and $12 \mathrm{~h}$ and a plateau at $12 \mathrm{~h}(+89,000 \%$ vs. pLP) (Figures 1A,B), while NAPEPLD was not detected in native $\mathrm{pLP}$ at the same time intervals. PEA concentrations significantly increased in the supernatant of pNAPE-LP, mirroring NAPE-PLD expression in a time and palmitate-dependent manner. The PEA level peaked at $12 \mathrm{~h}$ 
A

wild type

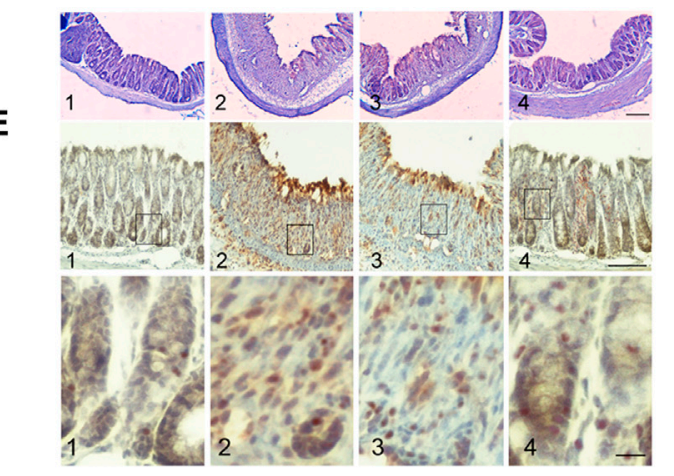

C

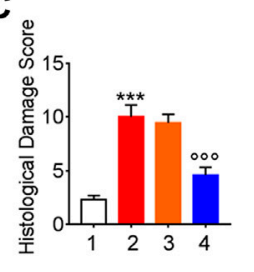

G

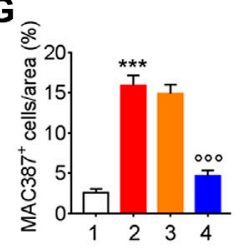

$1 \square$ Vehicle

2 TcdA $50 \mathrm{ng} / \mathrm{ml}$

3 TcdA $50 \mathrm{ng} / \mathrm{ml}+$ pLP+palmitate $0.0003 \mu \mathrm{g} / \mathrm{ml}$

4 TcdA $50 \mathrm{ng} / \mathrm{ml}+$ pNAPE-LP +palmitate $0.0003 \mu \mathrm{g} / \mathrm{ml}$

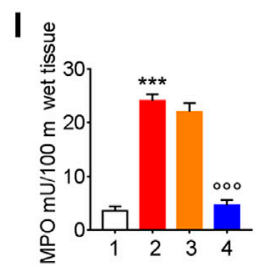

B

PPAR $\alpha$ KO

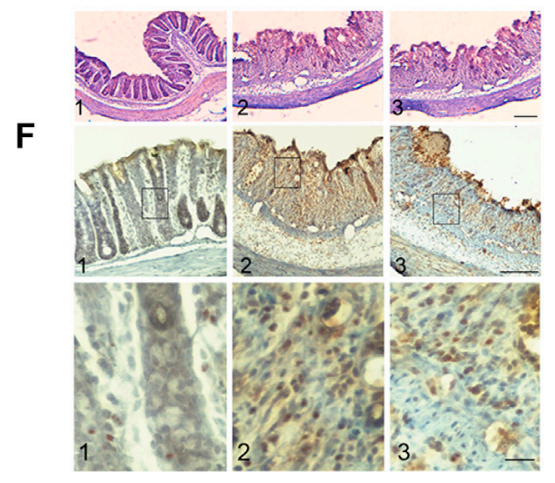

D

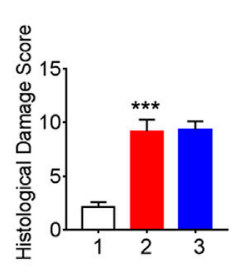

H

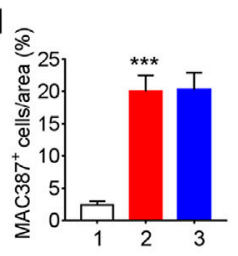

$1 \square$ Vehicle

2. TcdA $50 \mathrm{ng} / \mathrm{ml}$

3. TcdA $50 \mathrm{ng} / \mathrm{ml}+$ pNAPE-LP + palmitate $0.0003 \mu \mathrm{g} / \mathrm{ml}$

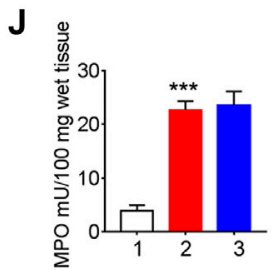

FIGURE 3 | Prophylactic administration of pNAPE-LP and ultralow palmitate dose accounts for histological damage attenuation with macrophage and neutrophils infiltration reduction in TcdA challenged mice. Hematoxylin and eosin ( $\mathrm{H}$ and $\mathrm{E})$ stained distal colonic specimens and (A, B) relative histological damage score showing the protective and PPARa-dependent effect of pNAPE-LP/palmitate treatment on TcdA-induced colonic injury (C, D) in both wild type and PPARa mice (magnification 4x, scale bar: $100 \mu \mathrm{m}$ ). Figure also shows the effect of pNAPE-LP/palmitate association on the immunohistochemical expression of MAC387 positive cell (marker of macrophage density) in distal colonic sections deriving from wild type and PPARa KO mice (E, F) (magnification 10x and 40x, scale bar: 100 and 50 $\mu$ m, respectively) and its relative quantification (G, $\mathbf{H})$, and the myeloperoxidase (MPO) activity quantification (indirect evidence of neutrophils infiltration) in both mice types (J, K). Results are expressed as mean \pm SEM of $n=5$ experiments. ${ }^{\star \star \star} p<0.001$ vs. vehicle; ${ }^{000} p<0.001$ vs. TcdA-treated mice.

$(+27900 \%$ vs. pLP) and reached a plateau concentration at the same time interval (Figures 1A,B). As anticipated, PEA levels were undetectable in pLP, even in the presence of the highest palmitate concentrations $(0.0003 \mu \mathrm{g} / \mathrm{l})$ (Figures 1A, B).

\section{In vivo NAPE-PLD Expression and PEA Release by pNAPE-LP Engineered Bacteria}

At sacrifice, NAPE-PLD protein expression and PEA release were also evaluated in mice colonic tissues from the different experimental groups. Our data show that TcdA challenge, per se, increased NAPE-PLD expression and PEA release $(+336 \%$ and $+400 \%$, respectively, vs. vehicle), while the treatment with native pLP + palmitate $0.0003 \mu \mathrm{g} / \mathrm{ml}$ led to a further but not significant increase in NAPE-PLD expression and PEA release $(+21$ and $+8.95 \%$, respectively, vs. TcdA group).

Conversely, the treatment with pNAPE-LP + palmitate $0.0003 \mu \mathrm{g} / \mathrm{ml}$ resulted in a significant +85 and $+72 \%$ relative increase of NAPE-PLD expression vs. TcdA and pLP + palmitate
$0.0003 \mu \mathrm{g} / \mathrm{ml}$ treated mice, respectively. In line with NAPE-PLD expression, PEA concentrations in colonic specimens from pNAPE-LP + palmitate $0.0003 \mu \mathrm{g} / \mathrm{ml}$ treated mice were increased up to $+1233 \%$ vs. vehicle and $+150 \%$ vs. pLP + palmitate $0.0003 \mu \mathrm{g} / \mathrm{ml}$, respectively, treated groups (Figures 2A,C,E).

\section{Treatment with pNAPE-LP and Palmitate Improves Colonic Histopathological Damage, Macrophage Density, and Neutrophil Infiltration in WT Mice}

The TcdA challenge induced a severe mucosal damage evaluated at histopathological analysis performed by $\mathrm{H}$ and $\mathrm{E}$ (Figures 3A,C) in WT mice (+350\% vs. vehicle). Mucosal inflammation was featured by a markedly increased macrophage density in the colonic mucosa, as per immunohistochemical quantification of MAC387 positive cells $(+450 \%$ vs. vehicle) and by increased neutrophils infiltration, indirectly confirmed by the increased 
A

A wild type

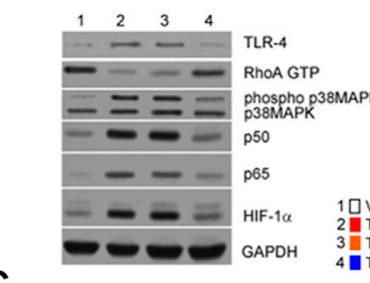

C
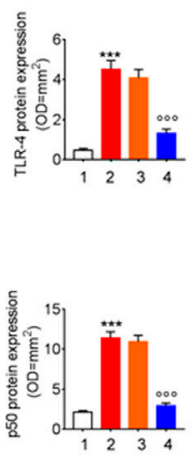

E

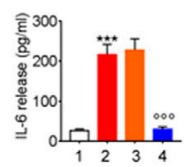

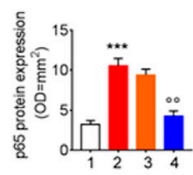
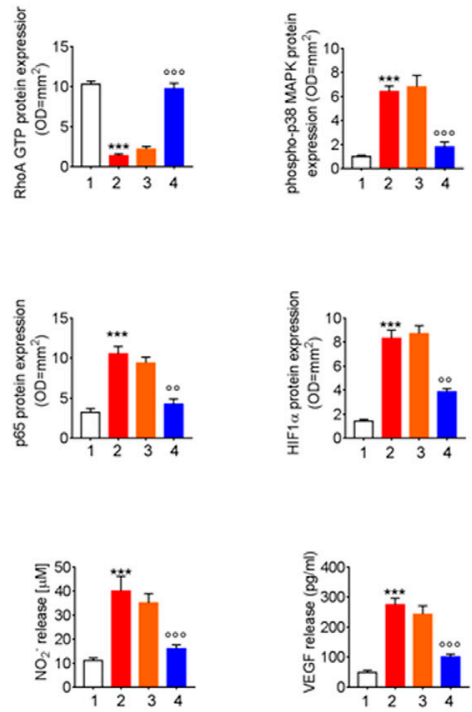

B

PPAR $\alpha$ KO

D

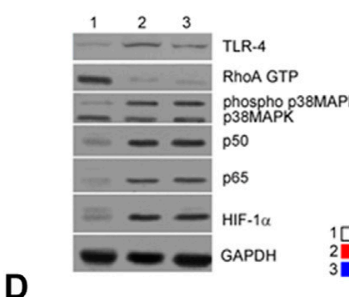

1. Vehicle 3. TCdA $50 \mathrm{ng} / \mathrm{ml}+$ pNAPE-LP + palmitate $0.0003 \mu \mathrm{g} / \mathrm{ml}$
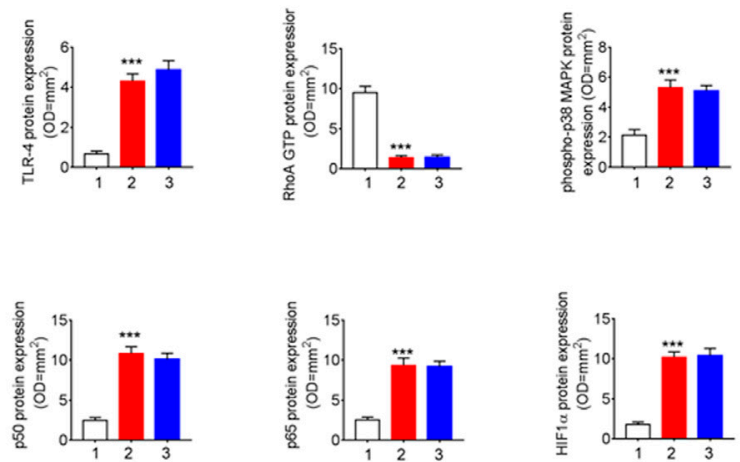

$\mathbf{F}$

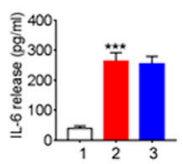

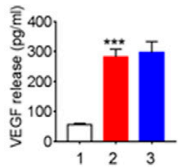

FIGURE 4 | Prophylactic administration of pNAPE-LP and ultralow palmitate administration on pro-inflammatory signaling molecules expression and release in mice colon. Immunoreactive bands showing TLR-4, RhoA GTP, phosphorylated/unphosphorylated - p38 MAPK, NF-kB-related p50 and p65, and HIF-1a protein expression in both wild type (A) and PPARa KO (B) mice following TcdA challenge and their relative PPAR $\alpha$-dependent decrease following pNAPE-LP/palmitate coadministration. Relative densitometric analysis (C, D) of each protein (arbitrary units normalized on the expression of the housekeeping protein GAPDH). Results were expressed as mean \pm SEM of $n=6$ experiments performed in triplicate. ${ }^{\star \star \star} p<0.001$ vs. vehicle; and ${ }^{000} p<0.001$ and ${ }^{00} p<0.01$ vs. TcdA. The figure also shows the effect of pNAPE-LP on TcdA challenged wild type (E) and PPARa KO mice (F) in terms of release of IL-6, nitric oxide (NO), and VEGF in the plasma. Results were expressed as mean \pm SEM of $n=6$ experiments performed in triplicate. ${ }^{\star \star \star} p<0.001$ vs. vehicle; and ${ }^{000} p<0.001$ vs. TcdA.

MPO activity (+633\% vs. vehicle) (Figures 3E,G,H). A negligible and not significant improvement in terms of histological score $(-6 \%)$, relative MAC387 density (-5\%), and MPO activity (-9\%) was observed in mice treated with native $\mathrm{pLP}+$ palmitate $0.0003 \mu \mathrm{g} / \mathrm{ml}$. On the contrary, pNAPE-LP + palmitate $0.0003 \mu \mathrm{g} / \mathrm{ml}$ administration significantly improved the histological damage score $(-53 \%)$, with a consequent reduction of MAC387 + cell count $(-70.4 \%)$ and a significant reduction in MPO levels $(-82 \%)$ compared to the TcdA group in WT mice.

\section{Treatment with pNAPE-LP and Palmitate Decreases Pro-Inflammatory Markers Expression and Cytokine Release in TcdA-Treated WT Mice}

The expression of pro-inflammatory signaling molecules and their release were evaluated in colonic tissue homogenates and plasma samples, respectively. Our results demonstrated that the intrarectal TcdA challenge caused a marked increase in the protein levels of TLR-4 (881\%), phospho-p38 MAPK $(550 \%)$, HIFla $(+489 \%)$, and of the markers of NF- $\mathrm{KB}$ activation p50 (433\%) and p65 (230\%), vs. vehicle in C57BL/6 J mice. Immunoblot analysis also revealed a massive decrease of RhoA-GTPase protein expression in TcdA vs. vehicle group (-87\%) (Figures $4 \mathbf{A}, \mathbf{C})$. In parallel, plasmatic levels of IL-6 $(+740 \%)$, NO $(+245 \%)$, and VEGF (458\%) were significantly increased in TcdA as compared to vehicle (Figure 4E).

pLP + palmitate $0.0003 \mu \mathrm{g} / \mathrm{ml}$ coadministration failed to improve the above-described parameters, as we observed a not significant variation in TLR-4 (-10\%), phospho-p38 MAPK $(+6 \%)$, HIF-1a (+5\%) p50 (-4.0\%), p65 (-10\%), and RhoAGTPase $(+9.5 \%)$ protein expression. Similarly, plasmatic proinflammatory mediators such as IL-6 $(+5.6 \%)$, $\mathrm{NO}(-10 \%)$, and VEGF $(-11 \%)$ were not significantly improved by native pLP + palmitate $0.0003 \mu \mathrm{g} / \mathrm{ml}$ vs. TcdA group.

Conversely, in the group of WT mice treated with pNAPE-LP + palmitate $0.0003 \mu \mathrm{g} / \mathrm{ml}$, we observed a reduced expression of pro-inflammatory signaling molecules with a significant decrease 
A

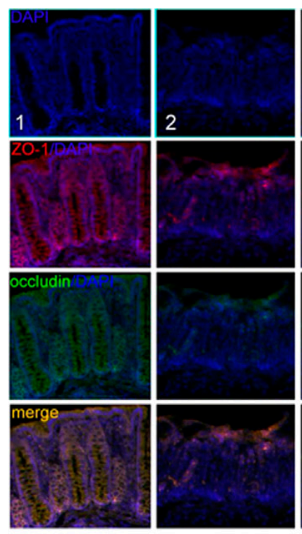

10 Vehicle

2 TcdA $50 \mathrm{ng} / \mathrm{ml}$

3 TcdA $50 \mathrm{ng} / \mathrm{ml}+$ pLP+palmitate $0.0003 \mu \mathrm{g} / \mathrm{ml}$

C

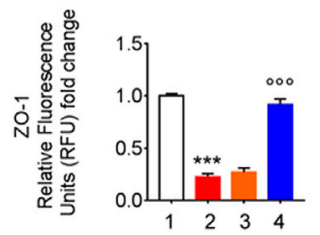

wild type

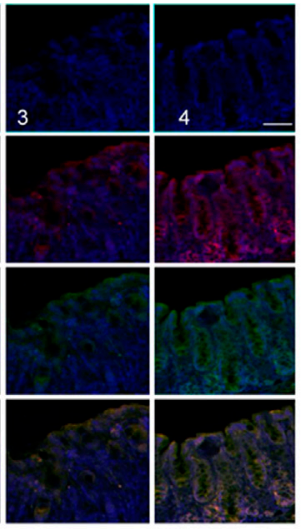

pLP+palmitate $0.0003 \mu \mathrm{g} / \mathrm{ml}$
pNAPE-LP + palmitate $0.0003 \mu \mathrm{gg} / \mathrm{ml}$

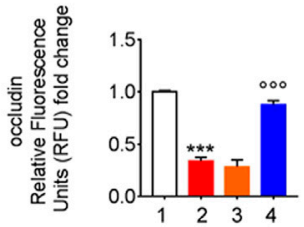

B

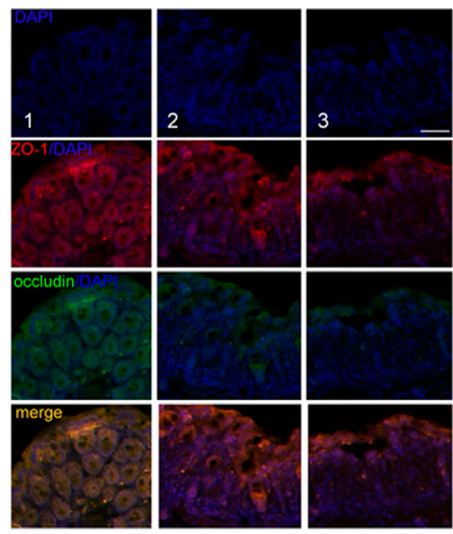

10 Vehicle

2 TcdA $50 \mathrm{ng} / \mathrm{ml}$

3] TCdA $50 \mathrm{ng} / \mathrm{ml}$ + pNAPE-LP + palmitate $0.0003 \mu \mathrm{g} / \mathrm{ml}$

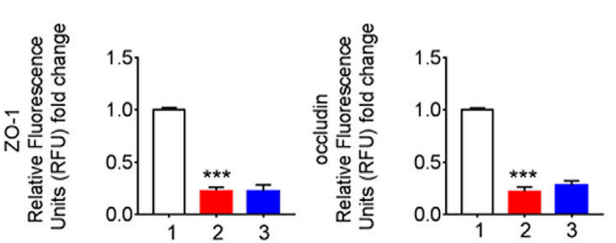

FIGURE 5 | PEA released from pNAPE-LP and ultralow palmitate co-administration restores TcdA-induced colon-barrier disruption, through the upregulation of tight junction proteins ZO-1 and occludin. Representative immunofluorescence images showing the expression of ZO-1 (red), occludin (green), and their merge (yellow) in both wild type (A) and PPARa KO (B) mice colonic specimen with their respective quantification (C, D) showing the PPARa-dependent protective effects of pNAPE-LP combined to palmitate $(0.0003 \mu \mathrm{g} / \mathrm{kg})$ co-administration. Nuclei were also investigated using DAPI staining. Results are expressed as mean \pm SEM of $n=5$ experiments performed in triplicate. ${ }^{* \star *} p<0.001$ vs. vehicle; ${ }^{\infty} p<0.001$ vs. DSS-treated mice. Scale bar $=100 \mu$ m; magnification $10 \times$. Scale bar: $100 \mu$ m.

of TLR-4 (-71\%), phospho-p38 MAPK (-72\%), HIF-1a (-53\%), p50 $(-74 \%)$, and p65 (-60\%) expression as compared to the TcdA group. In line with this, pNAPE-LP + palmitate $0.0003 \mu \mathrm{g} /$ $\mathrm{ml}$ also caused a significant recovery of RhoA-GTPase expression $(+649 \%)$ and a significant inhibition of the systemic release of IL$6(-86 \%)$, NO $(-59 \%)$, and VEGF $(-71 \%)$.

\section{Treatment with pNAPE-LP and Palmitate Improves the Tight Junction Expression of ZO-1 and Occludin in TcdA-Treated WT Mice}

As a consequence of TcdA enterotoxicity, immunofluorescence analysis revealed a significant depletion of both ZO-1 and occludin protein expression, key factors regulating colonic mucosa integrity, as demonstrated by a severe loss of relative fluorescent units compared to vehicle.

Specifically, TcdA exposure caused a significant decrease of ZO-1 and occludin in C57BL/6 J mice treated with TcdA (-78\% and $-77 \%$, respectively vs. vehicle) (Figure 5A). A one-week course of pLP and palmitate did not improve both ZO-1 $(+18 \%)$ and occludin (-16\%) expression vs. TcdA group (Figure 5A), while pNAPE-LP + palmitate $0.0003 \mu \mathrm{g} / \mathrm{ml}$ significantly improved the tight junction protein expression, with a relative increase in fluorescence intensity for both $\mathrm{ZO}-1$ (+304\%) and occludin (160\%) in WT mice (Figures 5C).

\section{The Effects of pNAPE-LP and Palmitate are Selectively Mediated by PPARa Receptors}

In line with the findings in WT animals, the TcdA challenge caused a significant upregulation of colonic NAPE-PLD expression $(+300 \%)$ and PEA release $(+133 \%)$ also in PPARa KO mice. The treatment with pNAPE-LP + palmitate $0.0003 \mu \mathrm{g} /$ $\mathrm{ml}$ caused a significant relative increase in NAPE-PLD tissue expression and PEA release in PPAR $\alpha \mathrm{KO}$ mice, similarly to what observed in WT animals (+168 and $+207 \%$, respectively, compared to TcdA-treated mice (Figures 2B,D,F)).

Nonetheless, despite the increase in PEA tissue levels, the treatment with pNAPE-LP + palmitate $0.0003 \mu \mathrm{g} / \mathrm{ml}$ failed to display all the aforementioned protective effects on the histological damage score and pro-inflammatory markers and tight junction proteins' expression in this murine model. Indeed, under the same experimental conditions, pNAPE-LP + palmitate $0.0003 \mu \mathrm{g} / \mathrm{ml}$ administration failed to improve the histological damage score $(-5 \%)$, macrophage density count $(+1.5 \%)$, and MPO level quantification (+5\%) (Figures 3B,F,D, H,J), in spite of the increased tissue production of PEA. Conversely to WT 
animals, no significant changes were detected neither in the expression of TLR-4 (+13\%), RhoAGTPase (+3.7\%), phosphop38 MAPK (-3.7\%), HIF-1a (+1.8\%), p50 (-6.5\%), and p65 $(-1.5 \%)$ (Figures 4B,D) nor in the plasmatic levels of IL-6 $(+3.4 \%)$, NO $(-7 \%)$, and VEGF $(+5 \%)$ in pNAPE-LP + palmitate $0.0003 \mu \mathrm{g} / \mathrm{ml}$ treated PPARa $\mathrm{KO}$ mice vs. the respective TcdA group (Figure 4F), further confirming the role of PPARa receptors in mediating PEA effects. Finally, TcdA exposure caused a significant decrease of ZO-1 and occludin in PPARa KO mice treated with TcdA (-78 and $-77 \%$, respectively vs. vehicle), but once again, the rescue of ZO- 1 and occludin observed in WT animals treated with pNAPE$\mathrm{LP}+$ palmitate $0.0003 \mu \mathrm{g} / \mathrm{ml}$ appeared to be mediated by PPARa receptors, since both ZO-1 (-0.89\%) and occludin (+18\%) signal intensity were unmodified by pNAPE-LP + palmitate $0.0003 \mu \mathrm{g} /$ $\mathrm{ml}$ treatment in PPARa KO mice (Figures 5B,D). Taken together, these results suggest the crucial importance of PPARa receptors in mediating the effects of the engineered probiotic pNAPE-LP in our experimental conditions.

\section{DISCUSSION}

With the continuous rise in its incidence and recurrence, there has been an increasing interest toward the development of nonantibiotic-based therapies for $C$. difficile infection. The current treatment guidelines indeed, advise for the use of metronidazole and vancomycin as first-line treatment in CDI (McDonald et al., 2018); however, increasing concerns have been raised regarding the incidence of resistant strains and the rate of recurrence in successfully treated patients (Johnson, 2009). Being broad-spectrum antibiotics themselves, both metronidazole and vancomycin carry the potential to prolong the susceptibility to reinfection, by preventing the replenishment of the resident intestinal microflora and, in so doing, suppressing one of the most important protective colonization resistance factors from the host (Baines and Wilcox, 2015).

In this context, probiotics can, at least on paper, be effective in restoring the intestinal dysbiosis and play a protective role against CDI (Na and Kelly, 2011). Although Saccharomyces, Bifidobacterium, and Lactobacillus genera all carried a protective effect against C. difficile (Mills et al., 2018; Liu et al., 2020), the efficacy of probiotics for CDI prevention and/or treatment is currently limited. In keeping with this, we observed only a modest and not a significant effect in limiting the histopathological damage and regulating the epithelial tight junction protein expression of ZO-1 and occludin, following preventive administration of pLP in our murine model.

Aside from the obvious implication of regulating the host-microbiota imbalance, however, probiotics could serve as delivery systems of anti-inflammatory molecules able to limit CDI severity. Genetically engineered probiotics able to colonize and in situ express anti-inflammatory mediators could overcome some of the therapeutic failings in CDI. Feasibility of oral therapy against CDI by means of using engineered Lactobacillus able to express toxin-neutralizing antibodies was previously explored in a hamster model and showed therapeutic potential by reducing colonic inflammation and prolonging animals' survival (Andersen et al., 2016). In the current study, we explored the efficacy of an orally administered pNAPE-LP, in order to achieve an in situ delivery and release of PEA in the gastrointestinal tract, under the boost of ultralow doses of exogenous palmitate.

Our results show that pNAPE-LP was an effective strategy to produce PEA, both in vitro and in vivo. PEA is an endogenous bioactive lipid amide with pleiotropic homeostatic properties, including immune response regulation and inhibition of pain and inflammation, through the activation of PPARa receptors (Sarnelli et al., 2016b). These well-established immunomodulatory properties have been studied in a number of animal and human models featured by hyper-inflammation, such as osteoarthritis (Britti et al., 2017), neurodegenerative, (Beggiato et al., 2019) and, notably, in inflammatory bowel diseases (Pesce et al., 2018).

In our model, the prophylactic oral administration of pNAPELP was able to limit the severity of TcdA toxin-induced colitis by improving colonic mucosa histopathological damage and reducing the release of pro-inflammatory mediators in both colonic mucosa and plasma. The increase in PEA tissue levels was followed by a significant downregulation of p50 and p65, markers of NF- $\mathrm{KB}$ activation, a key signaling pathway involved in downstream regulating cytokine and intestinal pro-inflammatory mediators' release (Wullaert, 2010). Besides, neo-angiogenesis induced by the TcdA challenge in vivo has been recently reported as a contributing factor in CDI pathogenicity (Huang et al., 2019). PEA release by pNAPE-LP + palmitate $0.0003 \mu \mathrm{g} / \mathrm{ml}$ was followed by a significant reduction of HIF-1a expression, through the inhibition of NF- $\kappa B$ signaling pathway. Since it has been demonstrated that HIF-1 $\alpha$ activation prompts a rapid worsening of CDI pathology and mortality (Huang et al., 2019), our results highlight the importance of the control of the neoangiogenesis as a further protective mechanism of pNAPE-LP administration. This is confirmed by the mitigation of both NO and VEGF levels in our experimental conditions, that is, in line with the previous observations of an antiangiogenic effect of PEA in colon inflammatory conditions (Sarnelli et al., 2016a).

Among the different tight junction proteins, $\mathrm{ZO}-1$ and occludin are key regulators in paracellular permeability in epithelial cells and TcdA is known to mediate its effects on tight junction structure and function via inactivation of Rho proteins (Nusrat et al., 2001). In parallel, PEA release improved, at a protein level, the expression of tight junction proteins ZO-1 and occludin, on one hand and induced a significant rescue of RhoA GTPase, on the other. Although we did not evaluate mucosal permeability, these combined effects likely suggest a marked improvement in epithelial barrier integrity mediated by pNAPE-LP treatment.

In animal models of ulcerative colitis, PEA has previously showed therapeutic potential in improving the histopathological and clinical features of ulcerative colitis. In this models, PEA antiinflammatory effects were also closely related to the specific reduction of enteric glial cells (EGCs) activation during colitis, mediated by the selective targeting of the S100B/TLR4 axis (Esposito et al., 2014). EGCs mediate a key role in the maintenance of gut homeostasis ensuring the correct trophism of neurons in the enteric nervous system (Fornai et al., 2018), 
modulating oxidative stress, controlling epithelial barrier functions, and actively participating in intestinal inflammation, by acting as antigen presenting cells (Capoccia et al., 2015). Although exploring the exact pathways involved in TcdAinduced inflammation was beyond the purpose of the present study, one could speculate that pNAPE-LP beneficial effects could also be mediated by PEA ability to counteract EGCs activation, as demonstrated in different models of colitis (Borrelli et al., 2015; Ippolito et al., 2015).

Additionally, PEA is known for its "entourage effect" on the endocannabinoid system (ECS), being able to potentiate the effect of prototypical endocannabinoids, but not carrying their potential side effects (Davis et al., 2019). Interestingly, the non-psychotropic cannabinoid cannabidiol (CBD) was able to prevent the cytotoxic damage caused by TcdA in vitro cultured Caco-2 cells (Gigli et al., 2017). The observed increase in mucosal integrity and reduced cellular permeability in this study were mediated by the involvement of the cannabinoid-1 (CB-1) receptor. CBD is a very low-affinity $\mathrm{CB} 1$ ligand, that can nonetheless still affect $\mathrm{CB} 1$ receptor activity and the ECS in vivo in an indirect manner. Although it has been suggested that CBD is well tolerated and safe in humans at high doses and with chronic use, in vitro and in vivo studies showed potential drug metabolism interactions, cytotoxicity, and decreased CB receptor activity (Bergamaschi et al., 2011; Iffland and Grotenhermen, 2017).

On the contrary, PEA offers the prospect of modulating the ECS without any virtual side effects, owing to its inability of activating the CB receptors (Ambrose and Simmons, 2019). PEA belongs to the Autacoid Local Injury Antagonist (ALIA) amides family, a group of shortly lived lipids that is produced on demand and rapidly metabolized to their inactive metabolites (Okamoto et al., 2004). Since orally administered PEA has an unfavorable pharmacokinetic profile that could prevent an efficient therapeutic response in humans, many murine models use intraperitoneal administration of PEA at high doses in order to achieve its therapeutic effects (Gabrielsson et al., 2016). Hence, one main limiting factor to its clinical transability in humans is PEA often-unpredictable tissue concentrations following oral administration. Here, we demonstrated the feasibility of integrating into the murine microbiota, a genetically engineered probiotic, able to topically biosynthesize PEA, overcoming such limitations.

We used the L. paracasei subsp. paracasei F19, a widely used probiotic in clinical settings (Di Cerbo and Palmieri, 2013), that is, featured by its peculiar genetic stability and its ability to colonize and persist in the human intestine (Higl et al., 2007). Analogously to PEA, L. paracasei subsp. paracasei F19 is considered safe for human consumption, and during human trials, it showed the absence of adverse effects, even in subjects with underlying disorders, adding to the safety of our system.

One limitation of the current study is that NAPE-PLD gene is a key enzyme responsible for the production of several other bioactive lipids, including oleoyl-ethanolamine (OEA) and anandamide (AEA) and PEA production is often coupled by a relative increase of these bioactive compounds. Although we did not test their levels in our model, the evidence that the protective effects of pNAPE-LP were abolished in PPARa KO mice supports the idea that PEA release is the key factor in mediating such effects. Nonetheless, these so-called entourage effects are not to be excluded a priori when considering the potential therapeutic effects of pNAPE-LP.

Another potential setback is that we explored an acute intestinal disease model by intrarectally injecting mice with TcdA enterotoxin, with a relatively short timeframe between colitis induction and animals' euthanasia. This model has been chosen because it is highly reproducible and well validated and replicates the main pathological findings of CDI. Nonetheless, being a murine model of acute intestinal injury, the study design prevents us from drawing any definitive conclusions on the effects of pNAPE-LP in terms of microbiota modifications and/or chronic PEA effects following prolonged administrations. This study, indeed, was designed to provide proof of concept data demonstrating the clinical feasibility and effectiveness of this newly designed probiotic in CDI and to evaluate for the first time PEA anti-inflammatory effects in TcdA-induced colitis.

Despite these limitations, the results of the present study highlight the safety and effectiveness of pNAPE-LP that, by counteracting mucosal inflammation and restoring the epithelial barrier function, can improve TcdA-induced colitis in mice. Although further research is needed to evaluate the long-term, ecological, and environmental safety of this genetically modified organism in order to translate this approach in humans, this evidence supports, for the first time, the role of PEA and this genetically engineered probiotic in counteracting CDI in mice.

\section{DATA AVAILABILITY STATEMENT}

The raw data supporting the conclusions of this manuscript will be made available by the authors, without undue reservation, to any qualified researcher

\section{ETHICS STATEMENT}

The animal study was reviewed and approved by La Sapienza University's Ethics Committee.

\section{AUTHOR CONTRIBUTIONS}

GE and GS (conceptualization, supervision, and lead of the entire project), CC and MP (investigation and writing, equally contributed), LS, ADR, MV, RL, and GA (investigation and data analysis), and JL and WS (formal analysis, review, and editing). GE, CC, and MP equally contributed as first authors.

\section{FUNDING}

Partially funded by MIUR Grant for basic research funding, "FINANZIAMENTO ANNUALE INDIVIDUALE DELLE ATTIVITA' BASE DI RICERCA, GE”, LEGGE 11 DICEMBRE 2016 N.232. 


\section{REFERENCES}

Ambrose, T., and Simmons, A. (2019). Cannabis, cannabinoids, and the endocannabinoid system-is there therapeutic potential for inflammatory bowel disease? J. Crohns Colitis 13 (4), 525-535. doi:10.1093/ecco-jcc/jjy185

Andersen, K. K., Strokappe, N. M., Hultberg, A., Truusalu, K., Smidt, I., Mikelsaar, R.-H., et al. (2016). Neutralization of Clostridium difficile toxin B mediated by engineered lactobacilli that produce single-domain antibodies. Infect. Immun. 84 (2), 395-406. doi:10.1128/iai.00870-15

Baines, S., and Wilcox, M. (2015). Antimicrobial resistance and reduced susceptibility in Clostridium difficile: potential consequences for induction, treatment, and recurrence of C. difficile infection. Antibiotics 4 (3), 267-298. doi:10.3390/antibiotics4030267

Beggiato, S., Tomasini, M. C., and Ferraro, L. (2019). Palmitoylethanolamide (PEA) as a potential therapeutic agent in alzheimer's disease. Front. Pharmacol. 10, 821. doi:10.3389/fphar.2019.00821

Bergamaschi, M. M., Queiroz, R. H., Zuardi, A. W., and Crippa, J. A. (2011). Safety and side effects of cannabidiol, a Cannabis sativa constituent. Curr. Drug Saf. 6 (4), 237-249. doi:10.2174/157488611798280924

Borrelli, F., Romano, B., Petrosino, S., Pagano, E., Capasso, R., Coppola, D., et al. (2015). Palmitoylethanolamide, a naturally occurring lipid, is an orally effective intestinal anti-inflammatory agent. Br. J. Pharmacol. 172, 142-158. doi:10.1111/ bph.12907

Britti, D., Crupi, R., Impellizzeri, D., Gugliandolo, E., Fusco, R., Schievano, C., et al. (2017). A novel composite formulation of palmitoylethanolamide and quercetin decreases inflammation and relieves pain in inflammatory and osteoarthritic pain models. BMC Vet. Res. 13 (1), 229. doi:10.1186/s12917$017-1151-z$

Capoccia, E., Cirillo, C., Gigli, S., Pesce, M., D’Alessandro, A., Cuomo, R., et al. (2015). Enteric glia: a new player in inflammatory bowel diseases. Int. J. Immunopathol Pharmacol. 28 (4), 443-451. doi:10.1177/0394632015599707

Chen, S., Sun, C., Wang, H., and Wang, J. (2015). The role of Rho GTPases in toxicity of Clostridium difficile toxins. Toxins 7, 5254-5267. doi:10.3390/ toxins7124874

Davis, M. P., Behm, B., Mehta, Z., and Fernandez, C. (2019). The potential benefits of palmitoylethanolamide in palliation: a qualitative systematic review. Am. J. Hosp. Palliat. Care 36 (12), 1134-1154. doi:10.1177/1049909119850807

Di Cerbo, A., and Palmieri, B. (2013). Lactobacillus paracasei subsp. Paracasei F19; a farmacogenomic and clinical update. Nutr. Hosp. 28 (6), 1842-1850. doi:10. 3305/nutrhosp.v28in06.6831

Di Rosa, M., Radomski, M., Carnuccio, R., and Moncada, S. (1990). Glucocorticoids inhibit the induction of nitric oxide synthase in macrophages. Biochem. Biophys. Res. Commun. 172, 1246-1252. doi:10. 1016/0006-291x(90)91583-e

Esposito, G., Capoccia, E., Turco, F., Palumbo, I., Lu, J., Steardo, A., et al. (2014). Palmitoylethanolamide improves colon inflammation through an enteric glia/ toll like receptor 4-dependent PPAR- $\alpha$ activation. Gut 63 (8), 1300-1312. doi:10.1136/gutjnl-2013-305005

Fornai, M., Van Den Wijngaard, R. M., Antonioli, L., Pellegrini, C., Blandizzi, C., and De Jonge, W. J. (2018). Neuronal regulation of intestinal immune functions in health and disease. Neurogastroenterol Motil. 30 (12), e13406. doi:10.1111/ nmo.13406

Gabrielsson, L., Mattsson, S., and Fowler, C. J. (2016). Palmitoylethanolamide for the treatment of pain: pharmacokinetics, safety and efficacy. Br. J. Clin. Pharmacol. 82 (4), 932-942. doi:10.1111/bcp.13020

Gachet, M. S., Rhyn, P., Bosch, O. G., Quednow, B. B., and Gertsch, J. (2015). A quantitiative LC-MS/MS method for the measurement of arachidonic acid, prostanoids, endocannabinoids, $\mathrm{N}$-acylethanolamines and steroids in human plasma. J. Chromatogr. B 976-977, 6-18. doi:10.1016/j.jchromb.2014.11.001

Gigli, S., Seguella, L., Pesce, M., Bruzzese, E., D’Alessandro, A., Cuomo, R., et al. (2017). Cannabidiol restores intestinal barrier dysfunction and inhibits the apoptotic process induced by Clostridium difficile toxin A in Caco-2 cells. United Eur. Gastroenterol. J. 5 (8), 1108-1115. doi:10.1177/ 2050640617698622

Higl, B., Kurtmann, L., Carlsen, C. U., Ratjen, J., Först, P., Skibsted, L. H., et al. (2007). Impact of water activity, temperature, and physical state on the storage stability of Lactobacillus paracasei ssp. paracasei freeze-dried in a lactose matrix. Biotechnol. Prog. 23 (4), 794-800. doi:10.1021/bp070089d

Hirota, S. A., Iablokov, V., Tulk, S. E., Schenck, L. P., Becker, H., Nguyen, J., et al. (2012). Intrarectal instillation of Clostridium difficile toxin A triggers colonic inflammation and tissue damage: development of a novel and efficient mouse model of Clostridium difficile toxin exposure. Infect. Immun. 80, 4474-4484. doi:10.1128/iai.00933-12

Huang, J., Kelly, C. P., Bakirtzi, K., Villafuerte Gálvez, J. A., Lyras, D., Mileto, S. J. et al. (2019). Clostridium difficile toxins induce VEGF-A and vascular permeability to promote disease pathogenesis. Nat. Microbiol. 4 (2), 269-279. doi:10.1038/s41564-018-0300-x

Iffland, K., and Grotenhermen, F. (2017). An update on safety and side effects of cannabidiol: a review of clinical data and relevant animal studies. Cannabis Cannabinoid Res. 2 (1), 139-154. doi:10.1089/can.2016.0034

Ippolito, C., Segnani, C., Errede, M., Virgintino, D., Colucci, R., Fornai, M., et al. (2015). An integrated assessment of histopathological changes of the enteric neuromuscular compartment in experimental colitis. J. Cel. Mol. Med. 19 (2), 485-500. doi:10.1111/jcmm. 12428

Johnson, S. (2009). Recurrent Clostridium difficile infection: a review of risk factors, treatments, and outcomes. J. Infect. 58 (6), 403-410. doi:10.1016/j.jinf.2009. 03.010

Kim, J. M., Lee, J. Y., Yoon, Y. M., Oh, Y.-K., Youn, J., and Kim, Y. J. (2006). NFkappaB activation pathway is essential for the chemokine expression in intestinal epithelial cells stimulated with Clostridium difficile toxin A. Scand. J. Immunol. 63 (6), 453-460. doi:10.1111/j.1365-3083.2006.001756.x

Lessa, F. C., Winston, L. G., and Mcdonald, L. C. (2015). Burden of Clostridium difficile infection in the United States. N. Engl. J. Med. 372 (24), 2369-2370. doi:10.1056/nejmoa1408913

Li, R., Kim, M. H., Sandhu, A. K., Gao, C., and Gu, L. (2017). Muscadine grape (vitis rotundifolia) or wine phytochemicals reduce intestinal inflammation in mice with dextran sulfate sodium-induced colitis. J. Agric. Food Chem. 65 (4), 769-776. doi:10.1021/acs.jafc.6b03806

Liu, D., Zeng, L., Yan, Z., Jia, J., Gao, J., and Wei, Y. (2020). The mechanisms and safety of probiotics against toxigenic Clostridium difficile. Expert Rev. Antiinfective Ther. 18 (10), 967-975. doi:10.1080/14787210.2020.1778464

Markham, N. O., Bloch, S. C., Shupe, J. A., Laubacher, E. N., Washington, M. K., Coffey, R. J., et al. (2020). Murine intrarectal instillation of purified recombinant $C$. difficile toxins enables mechanistic studies of pathogenesis. Infect Immun. IAI.00543-20. doi:10.1128/IAI.00543-20

Mcdonald, L. C., Gerding, D. N., Johnson, S., Bakken, J. S., Carroll, K. C., Coffin, S. E., et al. (2018). Clinical practice guidelines for Clostridium difficile infection in adults and children: 2017 update by the infectious diseases society of America (IDSA) and society for healthcare epidemiology of America (SHEA). Clin. Infect. Dis. 66 (7), 987-994. doi:10.1093/cid/ciy149

Mills, J. P., Rao, K., and Young, V. B. (2018). Probiotics for prevention of Clostridium difficile infection. Curr. Opin. Gastroenterol. 34 (1), 3-10. doi:10.1097/mog.0000000000000410

Mullane, K. M., Kraemer, R., and Smith, B. (1985). Myeloperoxidase activity as a quantitative assessment of neutrophil infiltration into ischemie myocardium. J. Pharmacol. Methods 14 (3), 157-167. doi:10.1016/01605402(85)90029-4

$\mathrm{Na}, \mathrm{X}$., and Kelly, C. (2011). Probiotics in clostridium difficile infection. J. Clin. Gastroenterol. 45 (Suppl. 1), S154-S158. doi:10.1097/mcg.0b013e31822ec787

Napolitano, L. M., and Edmiston, C. E., Jr. (2017). Clostridium difficile disease: diagnosis, pathogenesis, and treatment update. Surgery 162 (2), 325-348. doi:10.1016/j.surg.2017.01.018

Nusrat, A., Von Eichel-Streiber, C., Turner, J. R., Verkade, P., Madara, J. L., and Parkos, C. A. (2001). Clostridium difficile toxins disrupt epithelial barrier function by altering membrane microdomain localization of tight junction proteins. Infect. Immun. 69 (3), 1329-1336. doi:10.1128/iai.69.3.1329-1336. 2001

Okamoto, Y., Morishita, J., Tsuboi, K., Tonai, T., and Ueda, N. (2004). Molecular characterization of a phospholipase D generating anandamide and its congeners. J. Biol. Chem. 279 (7), 5298-5305. doi:10.1074/jbc.m306642200

Pesce, M., D’alessandro, A., Borrelli, O., Gigli, S., Seguella, L., Cuomo, R., et al. (2018). Endocannabinoid-related compounds in gastrointestinal diseases. J. Cell Mol Med 22 (2), 706-715. doi:10.1111/jcmm.13359 
Petrosino, S., and Di Marzo, V. (2017). The pharmacology of palmitoylethanolamide and first data on the therapeutic efficacy of some of its new formulations. Br. J. Pharmacol. 174, 1349-1365. doi:10.1111/bph.13580

Sarnelli, G., D’alessandro, A., Iuvone, T., Capoccia, E., Gigli, S., Pesce, M., et al. (2016a). Palmitoylethanolamide modulates inflammation-associated vascular endothelial Growth factor (VEGF) signaling via the akt/mTOR pathway in a selective peroxisome proliferator-activated receptor alpha (PPAR- $\alpha$ )-Dependent manner. PLoS One 11 (5), e0156198. doi:10.1371/journal.pone.0156198

Sarnelli, G., Gigli, S., Capoccia, E., Iuvone, T., Cirillo, C., Seguella, L., et al. (2016b). Palmitoylethanolamide exerts antiproliferative effect and downregulates VEGF signaling in caco-2 human colon carcinoma cell line through a selective PPARa-dependent inhibition of akt/mTOR pathway. Phytother. Res. 30(6), 963-970. doi:10.1002/ptr.5601

Schäffler, H., and Breitrück, A. (2018). Clostridium difficile - from colonization to infection. Front. Microbiol. 9, 646. doi:10.3389/fmicb.2018.00646

Terry, S., Nie, M., Matter, K., and Balda, M. S. (2010). Rho signaling and tight junction functions. Physiology 25, 16-26. doi:10.1152/physiol.00034.2009

Thoree, V., Skepper, J., Deere, H., Pele, L. C., Thompson, R. P. H., and Powell, J. J. (2008). Phenotype of exogenous microparticle-containing pigment cells of the human Peyer's patch in inflamed and normal ileum. Inflamm. Res. 57 (8), 374-378. doi:10.1007/s00011-007-7216-x
Wullaert, A. (2010). Role of NF- $\kappa B$ activation in intestinal immune homeostasis. Int. J. Med. Microbiol. 300 (1), 49-56. doi:10.1016/j.ijmm.2009.08.007

Disclaimer: Nextbiomics s. r.l has the status of Academic Spin-off of the University "Federico II" of Naples and should not therefore be perceived as a commercial conflict of interest.

Conflict of Interest: Authors GE, WS, and GS are affiliated with Nextbiomics s. r.l., Naples, Italy.

The remaining authors declare that the research was conducted in the absence of any commercial or financial relationships that could be construed as a potential conflict of interest.

Copyright (C) 2021 Esposito, Corpetti, Pesce, Seguella, Annunziata, Del Re, Vincenzi, Lattanzi, Lu, Sanseverino and Sarnelli. This is an open-access article distributed under the terms of the Creative Commons Attribution License (CC BY). The use, distribution or reproduction in other forums is permitted, provided the original author(s) and the copyright owner(s) are credited and that the original publication in this journal is cited, in accordance with accepted academic practice. No use, distribution or reproduction is permitted which does not comply with these terms. 